\title{
A Genre-Inspired Investigation of Establishing the Territory in Thesis Introductions by Malaysian ESL Writers
}

\author{
SITI ZAIDAH ZAINUDDIN \\ Faculty of Languages and Linguistics \\ University Malaya, Malaysia \\ AZIANURA HANI SHAARI \\ Faculty of Social Sciences and Humanities, \\ Universiti Kebangsaan Malaysia, Malaysia \\ azianura@ukm.edu.my
}

\begin{abstract}
This study looks at how ESL writers establish their research territory in their introductory chapters within the Applied Linguistics discipline. Eight PhD theses from three public universities were identified and selected as sample. The theses were chosen based on four criteria. The two disciplines selected were social sciences and humanities. This is to make sure that the corpora are similar in terms of the variation of the textual patterns. The analysis was performed using Swales' (1990) CARS model. This study employed a systematic analysis that balances the functional-semantic approach in the identification of moves and the constituent steps involved in a particular social event. The genre-based investigation reveals that even though the moves follow that of Swales' (1990) CARS model, the steps are different. Apart from that, this study also finds that a step can also be realised by several sub-steps after utilising a functional-semantic analysis to coding. Based on the findings, some practical implications of the research, in the form of suggestions for teaching masters and doctoral candidates about the construction and use of rhetorical strategies, from Malaysian and international perspectives are presented.
\end{abstract}

Keywords: Thesis introduction; CARS model; ESL writers; genre-based investigation; functional-semantic analysis

\section{INTRODUCTION}

Novice researchers have often found it difficult to write a thesis introduction as it involves several overlapping rhetorical strategies. They have to inform readers of the research area and must also explain why the proposed research is worthy. To ensure that their academic peers accept their propositions, novice researchers attempting to write an introduction must be equipped with adequate genre knowledge. One important rhetorical move is that writers must initially establish the research area before putting forward an argument that their study is significant enough to be carried out. The present study aims to look at how ESL writers establish their research territory in their $\mathrm{PhD}$ thesis introduction. This is to prove that investigating rhetorical move is important as it can inform us about the strategies employed before writers situate their study.

\section{THEORETICAL APPROACH}

In proposing a framework for analysing territory establishment, a genre-based investigation from the English for Specific Purposes (ESP hereafter) camp is applied. A common working definition of genre in this camp comes from Swales' (1990) seminal work involving two important facets, which are communicative purposes and discourse community. ESP practitioners, according to Cheng (2011), believe that the communicative purposes of a genre are conveyed in a sequenced manner, with a text being built up schematically through a series 
of moves and steps. In this regard, Swales (1990), when investigating the introductions of research articles (RAIs hereafter) found a three-move scheme that he later termed as the Create a Research Space (CARS hereafter) model. Moves can be viewed as spatial matters in which ideas move from one pre-formatted section to another (Swales, 1990).

In essence, the CARS (1990) model begins with a move (Move 1) that establishes the general topic by demonstrating the relevance and significance of the research. In doing this, the writer may use one or more of the three steps. Then, in Move 2, the writer creates a niche for the study within the territory in four steps. This is considered to be a critical move because it reveals the reasons and importance of the study. Lastly, in Move 3, the writer occupies the niche by introducing the present research by using one or more of the three steps. Swales (1990, p. 9) also highlighted that "...genre belongs to discourse communities, not to individuals".

The discourse community shapes not only the structures but also the content and style including the lexico-grammatical features of a genre. In recent decades, many discourseanalytic studies of written academic research, particularly RAIs, have utilised Swales' (1990) CARS model to examine texts from various fields, disciplines and languages. In addition, many cross-disciplinary and cross-cultural studies have used the CARS model as a template and analytical basis for analysing the move structure of theses as well as RAIs. Notwithstanding the extensive use of Swales' (1990) model, Samraj (2002) revisited the CARS model after reconsidering the moves and steps as well as input from research findings by several genre analysts that challenged the moves and their linearity. In the revised model, the steps to realise Move 1 have been reduced to one, namely topic generalisations of increasing specificity.

Hyland (2007) proposed several main purposes of genre analysis such as:

1. to identify how texts are structured in terms of functional stages

2. to identify the features that characterise texts and their communicative purposes

3. to discover how certain genres, relate to users' activities

4. to explain language choices in terms of the social, cultural and psychological contexts

From Hyland's (2007) description of genre analysis, it can be assumed that a researcher, (undertaking genre analysis in general) aims to discover how the structure of a text is organised and how the linguistic choices of a text define its communicative purpose.

Many genre studies have analysed how information is organised in academic research writing using Swales' (1990) CARS move/step analysis. In realising Move 1, three steps are identified. They are:

1. Step 1- claiming centrality (M1s1) which assures the reader that the theme of the topic under study is worth investigating and is well established.

2. Step 2- establishing topic generalisation and background information (M1s2) which presents overviews of the subject of the study.

3. Step 3- reviewing previous research (RPR hereafter) (M1s3) which reports on previous studies deemed to be relevant to the topic being discussed.

One of the key research findings of prior work on this topic relates to how texts are constructed and organised in systematic ways. However, studies analysing thesis introductions only at the move and step level mostly provide the macro part of thesis introductions. A detailed micro analysis that looks into the linguistic realisation of moves and steps has been somewhat ignored. Consequently, moves and their constituent steps differ.

Lim (2012, p. 233) reported that "when writers prefer to demonstrate a complete shift from Move 1 via Move 2 to Move 3, they display a much greater tendency to first highlight the specialised knowledge shared via published texts before presenting their personal judgment by 
pointing out a lacuna in previous research (rather than a claim about continuing a research tradition) between the preceding topic generalisation and the subsequent current work presentation." In another study, Lim $(2014$, p. 74$)$ also found that "in 'establishing a territory', an emphasis on the importance of researching a topic, combined with a description of a notable real-world problem that has been discovered and observed by the writer, may form the theoretical basis for a writer's argument that an issue is central and noteworthy".

Leshem et al. (2018) found a variety of styles among theses and nationalities. Writers from different countries employed different strategies and followed various moves in presenting their ideas. In their study, one of the South African writers, for instance, contextualises his study by discussing the national and institutional scenarios and describing the contexts (Move 1) before providing a comprehensive background of the research project (Move 3). Another writer from the United Kingdom, on the other hand, began her introduction with the need for the research (Move 2), followed by the policy and school contexts (Move 1). Among the reasons contributing to the different strategies of writing are cultural differences, institutional regulations (Leshem et al., 2018, p. 173), as well as genre-related factors (Kawase, 2018) such as disciplinary conventions and content organisation. Maznun et al. (2018) reported that "students were not clear about the structure and organisation of the introduction section. In Move 1, they were not aware of including the centrality claim. The probable reason might be that in the field of social science, the importance of reviewing past researches is more emphasised in the Literature Review than in the Introduction section" (Maznun et al., 2018, p. 14).

Their study extended the body of knowledge of how Malaysian ESL writers establish their research territory, which is by analysing the rhetorical and possible sub-steps. Thus, the present study aims to unpack the following question:

How do Malaysian ESL writers establish the territory of their studies within the Applied Linguistics discipline?

As this study examines thesis introduction written by non-native writers, it is noteworthy to explore the possible explanations on why Malaysian writers write the way they do.

\section{METHOD}

This study focuses on $\mathrm{PhD}$ theses rather than Master's theses because the former allows a more descriptive and critical evaluation. Data were collected using both qualitative and quantitative methods. On balance, it is predominantly a qualitative research since it focuses on relating the construction of meaning to the rhetorical organisation of written theses. However, some quantification of the units of analysis are used to assist the search for similarities and differences in how communicative purposes are achieved by different rhetorical strategies.

\section{BACKGROUND OF THE CORPUS}

The theses were chosen based on four criteria: university, field, ethnic group and location. Only theses from Malaysia's research universities (i.e. RU1, RU2 AND RU3) were chosen. The two disciplines selected were social sciences and humanities, not only to make the corpora as similar as possible, but also because of the prominent variation in textual patterns. Echoing Duszak (1997, p. 11), the communication styles in the humanities and social sciences "respond strongly to language and culture-bound discoursal preferences and constraints". The areas of 
studies were then restricted to English or Educational Studies. In addition to considering these fields, only recent postgraduate students who completed their studies were selected. This must be taken into consideration since the temporal factor might also affect the rhetorical configuration of texts (Moreno, 2008), as genres are fluid and not of a fixed nature.

Finally, only eight theses were identified and selected as samples. Nine students graduated from RU1 but only four were Malays. The researchers identified three writers who were willing to participate. The three participants represent $75 \%$ of the total population of Malay $\mathrm{PhD}$ students from the chosen university. From $\mathrm{RU} 2$, ten $\mathrm{PhD}$ students graduated, with five being Malay. Three were chosen as they live and/or work in Selangor and Kuala Lumpur, hence the data from this university comprises $60 \%$ of the population of Malay $\mathrm{PhD}$ students. From RU3, six PhD students graduated from two faculties: Faculty of Education and Faculty of Social Sciences and Humanities. Of the six theses, only three were written by Malay students, two of whom resided in Selangor and the other in Sarawak; hence the writers from Selangor were chosen for this study. Therefore, the data from RU3 comprises $70 \%$ of the total population of Malay PhD students in that university.

\section{DATA ANALYSIS}

The study referred to Kwan's (2006) and Lewin et al.'s (2001) semantic-functional approach as well as Samraj's (2005) notion of "phenomenon in the real world" and "research-world knowledge". The basis of their semantic network is based on a realisation criterion that says, in realising a move, a statement must contain at least one of the following participants:

a) a research (product or producer)

b) the phenomena being studied; and/or

c) the population affected by the phenomena where each participant should bear some form of "attribute"

In resolving the extent of the unit of analysis, they concurred that a rhetorical function is realised by the communicative purpose of the texts and cannot be constrained by a set of grammatical units such as a sentence or a clause. Constraining moves into a segment of text does not seem reasonable, especially for a longer text such as the thesis introductions analysed in this study.

Functional approach was incorporated into the analysis since the semantic approach was insufficient to code the data. The findings of Ventola (1987) and Hunston (1989) concur that structural divisions in texts should be viewed and analysed cognitively. Bhatia (1993) also maintained that, at certain points, we need to resort to cognitive judgement rather than linguistic criteria to identify textual boundaries. Thus, when coding a segment of text using a functional approach, Kwan (2006) suggested that the analyst ask questions such as "how does this segment help achieve the local purpose and what is the macro purpose of the text?" 


\section{FINDINGS}

\section{FREQUENCY OF MOVES}

All the moves in thesis introductions are obligatory. This section analyses the frequency and location of each move. The frequency of occurrence for each move may show the writers' choices and, indirectly, further enhance our understanding of how ESL writers in the present study strategised their writing. Figure 1 presents the amount of attention afforded to each move across all eight introductory chapters examined in this study.

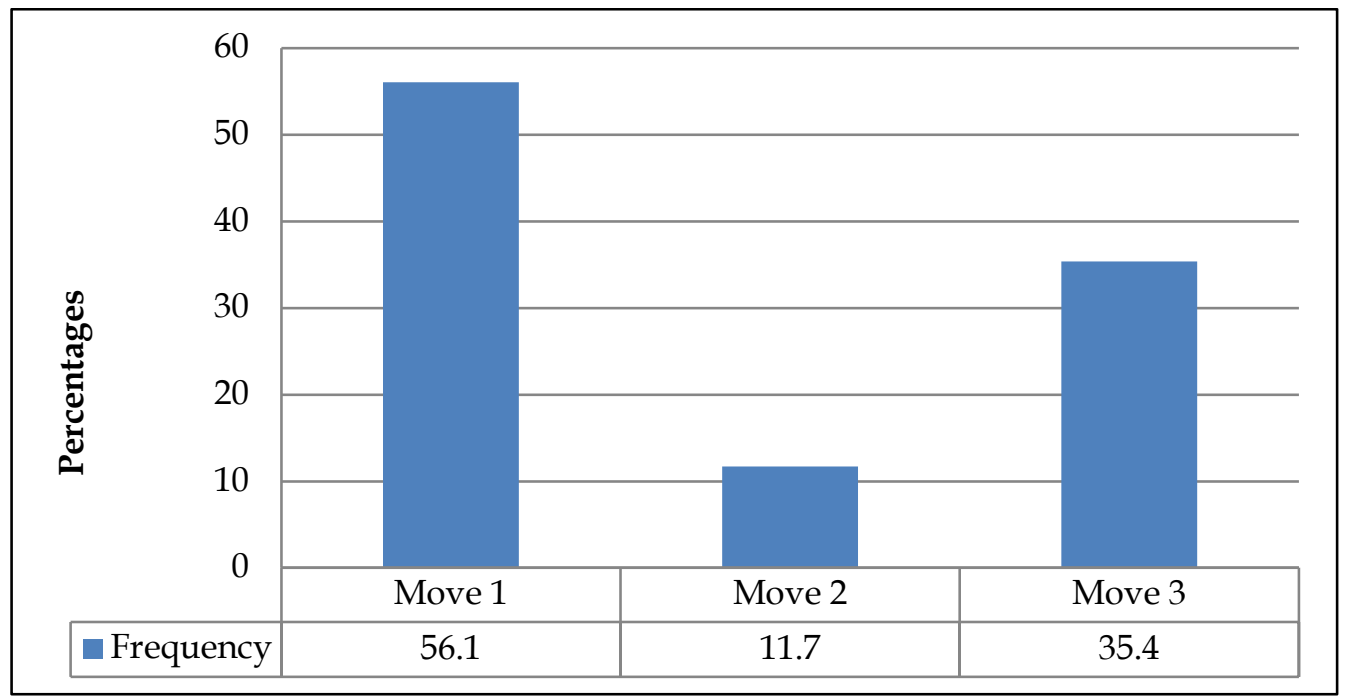

FIGURE 1. Percentages of moves

Although all three moves in Swales' (1990) CARS model occurred in the eight thesis introductions, these moves are unevenly distributed in the corpus. Figure 1 shows that Move 1 occurred most frequently with more than $50 \%$ of the total number of frequency occurrence. Move 2, on the other hand, was the least frequent move with only $11.7 \%$. It suggests that the introductory section of a thesis demands that the writer provides a map of the existing territory.

\section{STEPS AND SUB-STEPS OF MOVE 1: ESTABLISHING THE TERRITORY}

Consistent with Move 1 of Swales' (1990) CARS framework, establishing the territory in the corpus is also realised in three variations or steps. Specifically, the highest frequent occurrence was M1s2 with $83 \%$, followed by M1s1 which was at $12 \%$. The least frequent step was RPR. Figure 3 summarises these findings on the distribution of the frequency of steps in Move 1. 


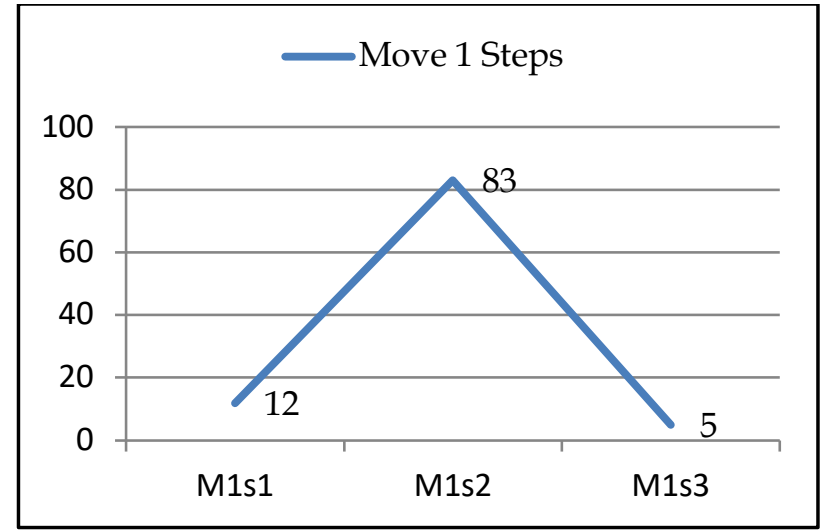

FIGURE 2. Frequency occurrence of Move 1 steps

Figure 2 clearly suggests that writers considered presenting an extensive background of their topic to provide background knowledge for readers. M1S2 has the second highest occurrence and three sub-steps were found in realising M1s2. They are:

M1ss2a: reporting what is known

M1ss2b: identifying problems and needs at the background level

M1ss2c: anticipating the solution

The small percentage for Step 3 has several possible implications. One could be that RPR is the least important and least preferred strategy among writers. Another implication could be that writers do not provide enough evidence for a critical discussion of their perspectives of what RPR is. Since the occurrence is small, the paper will not discuss this step in detail. However, it is important to note that that a critical discussion of RPR can provide two benefits. Firstly, a detailed analysis of RPR in the text can provide a general perspective of what RPR represents from the writers' point of view. Secondly, this perspective would benefit future research writers when writing academic research texts.

The overall steps and sub-steps of Move 1 are summarised in Table 1.

TABLE 1. The overall steps of Move 1

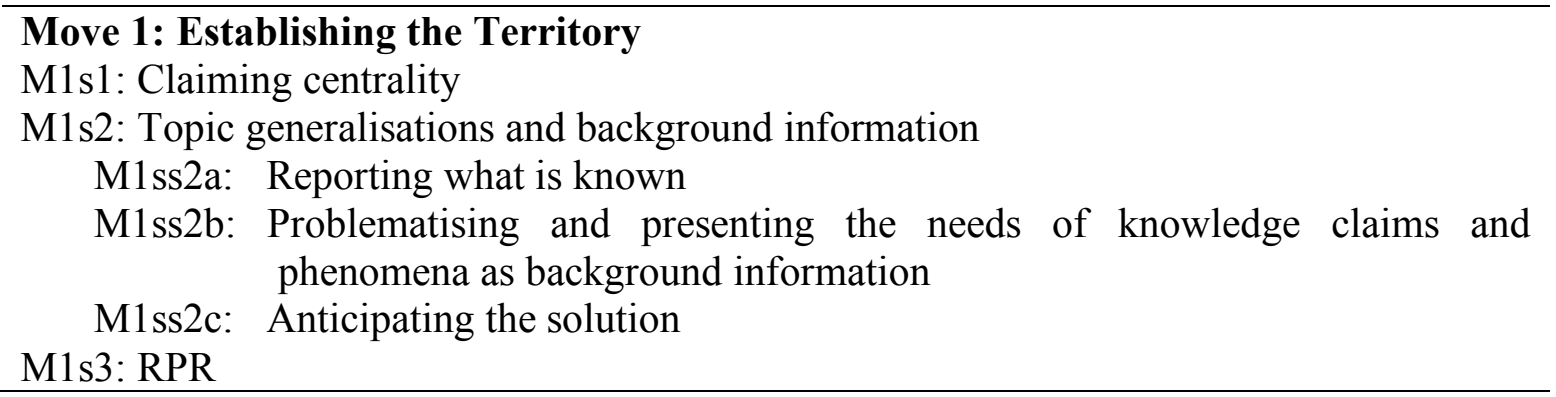

\section{M1s1: Claiming Centrality}

Step 1 of Move 1 focuses on the claim that the research topics are significant in some ways. Figure 2 shows that the percentage of usage is low with only 12 percent of all steps in Move 1 . The findings also indicated that all thesis writers employed this step and regarded Step 1, which is claiming centrality. 
The detailed move-step sequence in each thesis show that six writers begin their introductory chapter with a statement(s) of Claiming Centrality. It seems that all the opening statements of Theses 1-6 consist of the theme, where they assert their value in terms of magnitude, salience and relevance to the study in general. This can be seen from the lexical items core, sudden, increasing, ultimate and uncontested. Many Claiming Centrality statements in the theses make many assertions about the phenomenon being investigated, compared to reviewing it as a form of active (on-going or completed) research.

\section{(i) Locations and style configurations}

Statements of Centrality Claims were most commonly found co-occurring with other Move 1 statements in the early part of the Introductions. An example of the first configuration is shown in Example 1.

\section{Example 1: Claiming Centrality Statements co-occurring with Move 1 in Thesis 3}

\begin{abstract}
The number of computer users in the education sphere is increasing daily. Much of the growth is attributed to educators and learners using the Internet. The widespread use of the Internet has resulted in expectations that information communication and technology (ICT) can enhance learning and would be able to provide high-quality education accessible to all. It has transformed the traditional delivery of education whereby educators, teachers, and linguists have seen pedagogic changes, from a teacher-centered teaching and learning environment to a learner-centered one. The Internet has dramatically changed the efficiency of information dissemination and human communication. Advances in ICT over the last two decades have placed schools and colleges in a unique position to take advantage of new learning opportunities. Coopers (2004) stated that online learning defined as the exploitation of interactive technologies and communication system to improve the learning experience in principle, reach into every part of the educational experience both in the classroom and increasingly outside the normal learning environment.
\end{abstract}

Line 1 in Example 1 shows how the writer starts by employing [m1s1], where the writer is claiming that there is an increase in the number of users of computers in education. The following sentence is a neutral statement. The lexical widespread in Line 3 continues the writer's stance on the growth of computer users. Lines 3 to 8 impart the outcome of the Internet. In Line $8,[\mathrm{~m} 1 \mathrm{~s} 1]$ is again utilised when the writer strongly declares and at the same time concludes that the Internet has changed and benefited communication. The time adjunct over the last two decades shows that the writer attempts to accentuate the impact of ICT. After the writer has emphasised the importance of the Internet, especially with reference to online learning, the paragraph concludes with a definition of what online learning is.

Claiming Centrality statements can also precede a Move 2 step. An excerpt from Thesis 5 is an example. Centrality statements in Thesis 5 presented in Example 2 refer to the importance of an integrated approach when conducting a study on creativity. It is then supported by citations of previous researchers to show that the concept has been accepted by many researchers. In establishing the research niche, the writer presents the problem and needs of the study. Finally, the writer informs the approach chosen for her study and justifies her decision. 


\section{Example 2: Claiming Centrality Statements precede Move 2 in Thesis 5}

Furthermore, recent trends in the studies of creativity indicate a growing concern toward an integrated approach, which "hypothesized that multiple components must converge for creativity to occur" (Amabile, 1983, 1996; Csikszentmihalyi, 1988; Gardner, 1993; Gruber, 1989; Lubart, 1994; Mumford \& Gustafson, 1988; Perkins, 1981; Simonton, 1988; Sternberg, 1985).

Creative process, for instance, cannot be studied in isolation and it M2s1b requires a...

The confluence approach has been selected for this study because...

M1s1
$M 2 s 1 b$
$M 3 s 10$

Centrality statements can also co-occur with Move 3 i.e. $[\mathrm{m} 1 \mathrm{~s} 1 / \mathrm{m} 3 \mathrm{~s} 2 / \mathrm{m} 1 \mathrm{~s} 1]$. In this study, it is a very rare rhetorical strategy as there is only one instance of this configuration. In Example 3, the writer asserts the importance of reading in the learning process and the attention it receives from researchers. However, the phrase "the primary focus of this study" suggests that the subject matter is the focus of her study.

\section{Example 3: Claiming Centrality Statement co-occurring with Move 3 in Thesis 2}

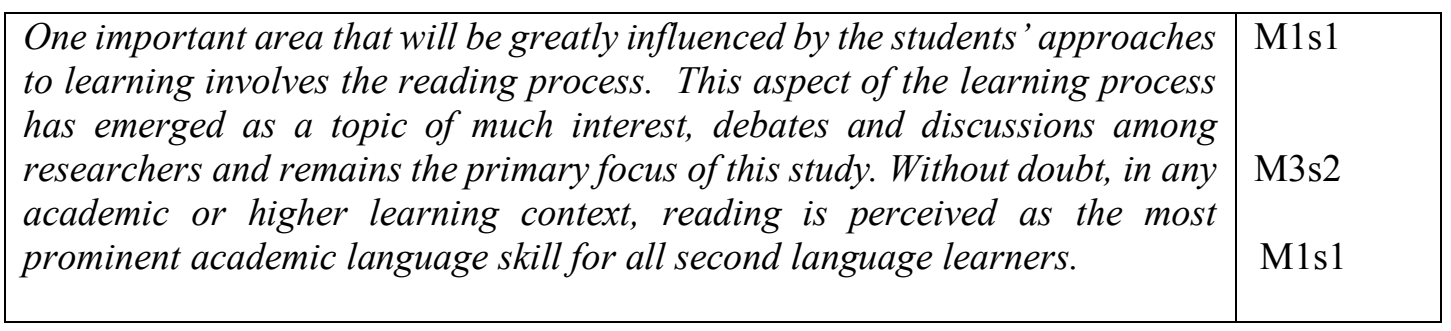

(i)

\section{Value of Centrality Claims}

As it has been pointed out before, Centrality Claims are events (phenomena or research) that can be generated from both the real world and the research world (Samraj, 2005). Throughout the thesis introductions, many Centrality Claims statements relate mainly to the value of magnitude and salience of the phenomena in the real world. The occurrence of realworld and research-world Centrality Claim statements in the introductory chapter is presented in Table 2.

TABLE 2. Real-world and research-world Centrality Claims

\begin{tabular}{lllllllllll}
\hline Thesis & T1 & T2 & T3 & T4 & T5 & T6 & T7 & T8 & Total & \% \\
\hline Real-world & 6 & 5 & 19 & 4 & 5 & 4 & 1 & 21 & 65 & 74 \\
Research-world & 1 & 3 & 5 & 1 & 4 & 0 & 4 & 5 & 23 & 26 \\
\hline
\end{tabular}

Seventy-four per cent of the total centrality claims were assertions showing general themes that have no direct relevance to the writers' research are most preferred by the thesis writers. Thesis 2, for example, began her introductory chapter with a general statement on how the life of a first-year student in university would be difficult compared to when they were in school. The writer did not focus on ESL students' approaches to reading an academic text which was the focus of the study. The excerpt in Example 4 below is the opening statement of the thesis: 


\section{Example 4: Centrality Claim statement of General Themes in Thesis 2}

Studying in the university for the first time would involve a sudden change in the way of life for most students.

It is quite common for these real-world statements of Claiming Centrality to aim for a certain degree of importance of a problem in the writers' country. Example 5 shows the writer beginning with a general understanding of communication in multicultural countries. The underlined parts highlight the claim of similar phenomena in Malaysia and that it has been a popular research topic because Malaysia is a multicultural and multilingual country.

\section{Example 5: Real-world Centrality Claim showing importance to the writer's country in Thesis 7}

Malaysia is no exception. Much has been said and studies [sic] about the language use or choice and preference of speakers when communicating within the multilingual and multicultural milieu in Malaysia.

Example 6 also shows the writer utilizing this type of rhetorical strategy extensively as a way to stress the mounting importance of online learning in Malaysia.

\section{Example 6: Real-world Centrality Claim showing importance to the writer's country in} Thesis 3

In the Malaysian scenario, online learning is not only a growing industry but also, potentially, an important vehicle for the provision of education, knowledge and information to the public.

Another common Centrality Claim points to assertions that the theme under study has been researched widely. There are few occurrences of Move 1 Step 1 of this criterion in the text samples. Two theses have the most occurrences of Centrality Claims but only little reference to the research issue as being an active rationale. Thesis 3 has only five instances of research-world knowledge as compared to nineteen real-world Centrality Claims. Thesis 8 has the highest number of Centrality Claims. However, only five claims were reported to be on active research. Example 7 from Thesis 8 reveals one of the claims:

\section{Example 7: Research-world Centrality Claim in Thesis 8}

In fact, corpus study has been around for the past forty years with pioneers like Kucera and Francis (1967). Johansson (1980) and colleagues produced a parallel corpus of British English that added another dimension of comparison.

Like the real-world statements of Centrality Claims, the statements of research-world Centrality Claims also point to the relevance of the writer's home country. Writer 7, for example, presented the scores of studies in the area of language and choice in Malaysia. Example 8 illuminates this point: 
3L: Language, Linguistics, Literature ${ }^{\circledR}$ The Southeast Asian Journal of English Language Studies Vol 27(2), June 2021 http://doi.org/10.17576/3L-2021-2702-11

\section{Example 8: Research-world Centrality Claim showing importance to the writer's country in Thesis 7}

The literature of the subject of language use and choice within the Malaysian multilingual settings is quite replete (Asmah, 1982; 1988; 1985; Morais, 1994; Anie, 1998; David, 1998; Kuang. 1999; Nair-Venugopal, 2000; Ain-Nadzimah, 2005; Rafik-Galea \& Fernandez, 2005).

Based on the semantic network by Lewin et al. (2001), it is found that participants consist of the phenomena, research product and research producers. The three attributes of participants are magnitude, intensity and salience. This schema is illustrated with excerpts taken from Thesis 1 and Thesis 2 in Example 9.

\section{Example 9: Semantic scheme of the realisation of claiming centrality in Theses 1 and 2}

(i) Phenomenon + intensity (real world) Communication is a core activity in the language classroom in both oral and written form.

(ii) Phenomena + magnitude (real world)

Thesis 1

Furthermore, globalization has also increased communicative links with countries all over the world for all types of business. This further strengthened the role of English as the common lingua franca for non-native speakers.

(iii) Phenomena + salience (real world + research world)

Thesis 1

One important area that will be greatly influenced by the students' approaches to learning involves the reading process. This aspect of the learning process has emerged as a topic of much interest, debates and discussions among researchers ...

Thesis 1

(iv) Research product + magnitude (research world)

A substantive body of research on students' initial experience of higher learning has identified many complex factors encountered by students in their transition from learning at school to learning at the university.

Thesis 2

(v) Research producers + magnitude (real world)

The application of information and communication technologies (ICT) has expanded greatly since the mid-1990 with the public universities taking the lead in offering online learning.

Thesis 2

Therefore, the centrality claims found in the corpus are research that is about to be reported as part of a lively, significant or well-established research area as Swales (1990) initially suggested. They are also research that can be generated from the real world and the research world as initially found by Samraj (2008). Finally, centrality claims show events which consist of participants that involve either the phenomena, research producers or research products. Each participant then should have elements of accentuated-ness which are magnitude, salience and intensity. Based on Lewin et al. (2001), magnitude refers to the accumulating-ness and accumulated-ness of the phenomenon for instance phrases like 'has been largely', 'has increased' and 'a substantive'. Salience relates to the significance or importance of the participant and Intensity suggests the degree of the claim. 
Centrality claim statements do not fully account for the totality of the rhetorical strategies used to develop Move 1. Another rhetorical function performed in Move 1 falls under topic generalisation and background information.

\section{M1s2: Topic Generalisation and Background Information}

This step corresponds to the second part of Move 1 as postulated by Lewin et al. (2001), namely reporting what is known in the field. Based on the scant attention given to making topic generalisations in the literature, insights into the semantic realisation of this step are therefore limited. Nevertheless, the current study drew on Swales (1990), Lewin et al. (2001) and Kwan (2006) to understand the concept and approach to the analysis. Together, it is found that M1s2 in the corpus has three main categories: M1ss2a: Reporting what is known; M1ss2b: Problem and need at the background level; and M1ss2c: Anticipating the solution. The analysis of the data showed extensive use of M1ss2a which made up more than half of the overall Step 2 strategies employed (76\%). The thesis writers also relied heavily on M1ss2b in an attempt to create the research space. The least used step was M1ss2c, with less than five per cent usage.

\section{M1ss2a: Reporting on 'what is known'}

An M1ss2a statement in the study reports the established/existing real-world phenomena and it is composed of neutral and general statements. It carries the semantic features of the definition of the terms, categorisation of the concepts/theories/underlying themes of the study, and presentation of the historical events. Statements of this type also describe the phenomena through the findings of previous research. The realisation of M1ss2a statements can be seen in Figure 3.

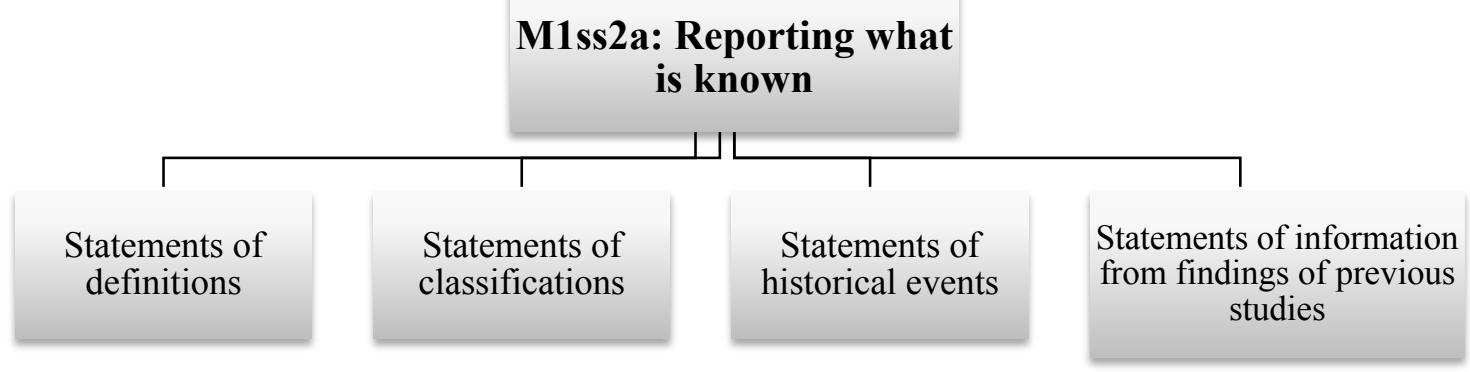

FIGURE 3. Realisation of M1ss2a statements

The statements of definitions in the study indicate the specificity of terms, concepts or theories and make clarifications and/or exemplifications of terms, concepts or theories. Statements attributing to clarification and exemplification are not distinct, but they simultaneously facilitate denoting a theory or concept. When defining a term/theory/concept, a broad spectrum is used from vague or explicit to implicit. There are a number of recognised ways to define terms or concepts which include making a statement of equivalence where propositions have the same truth value and elucidating when the head proposition is vague and lax. A statement of equivalence can be coded when the verbs used to make the definition are explicit, for instance, "defines... as" or “...is...”. An example can be seen in Example 10. 


\section{Example 10: Statement of Definition in Thesis 2}

Ramsden (1992) defines studying in higher education as "an understanding of key concepts; an ability to go beyond the orthodox and the expected so that the hitherto unmet problems can be tackled with spirit; and - closely associated with the previous point an awareness of what learning and understanding in the discipline consists of"

When the elucidation of the head proposition is vague and lax, terms such as "define" are easily and explicitly understood. However, some terms such as "describes" and "involves" are applied in a loose way. An excerpt from Thesis 1 is given in Example 11.

\section{Example 11: Statement of Definition in Thesis 1}

The "deep approach" describes students who began with an intention of understanding the meaning of the article and would then interact actively with the task until maximum meaning was extracted. On the other hand, the "surface approach" describes students whose original intentions were to satisfy course requirements, resulting in memorizing information without "developing any significant understanding of it" (Entwistle \& Ramsden, 1983; Entwistle, 1997b). Later, a third category of approach was identified strategic - where students started with the intention of getting the highest possible marks or grades leading them to engage in whatever strategies necessary to earn high marks (Biggs, 1987).

Another sub-step is to provide the statements of classifications. The excerpt in Example 12 shows the writer's intention to explain a particular concept as the background of the study. In doing so, the writer informs the theory of "conceptions of learning" by indicating the categorisation of the concept.

\section{Example 12: Statement of classification in Thesis 2}

The first three of these conceptions reflect learning that involves lower level cognitive processing, or "quantitative", such as rote-memorization and imitation. The last three refer to qualitative-type of learning that involves developing higher level cognitive processing, such as, understanding meaning of information and relating new information (Chalmers \& Fuller, 1996).

The study also found that statements attributing to historical events can also realise M1ss2a statements. This kind of statement presents chronicles of historical events to provide background information. An example is shown in Example 13 where the statement is located under the sub-heading Language Education in Malaysia. In fact, the whole paragraph is dedicated to the history of Malaysian education from the British colonial era to the present as well as to policy development.

\section{Example 13: Statement of historical event in Thesis 1}

The system of education in Malaysia was administered by the British in the early $19^{\text {th }}$ century in accordance with their policy of "divide and rule" that reflects their colonial policy.

The sub-step M1ss2a: Reporting what is known in the present study can also be realised by statements of information from findings of previous studies. A statement of previous research is considered to be topic generalisation if the findings presented do not indicate the 
semantic features of any research event such as the research instruments (e.g. questionnaires, interviews) and research design (e.g. ethnographic studies). The statement basically foregrounds the findings as established/existing knowledge rather than as specific research events. Two excerpts from Thesis 2 are provided in Example 14. The deliberateness of the writer to avoid offering research signals in these statements shows that the main function or intention is only to present the findings without being analytical.

\section{Example 14: Statements of previous research in Thesis 2}

In a study conducted by Ramsden (1988) on final year students, findings reveal that many were able to apply complex skills in science, mathematics and humanities as well as reproduce large quantities of factual information and pass examinations.

In reading in the second language for example, many poor readers have been found to be uninitiated and uninterested to read due to several factors, such as lack of vocabulary knowledge, difficult text as well as low language proficiency (Anderson, 1991, Ushioda, 2001).

One unique characteristic of the present corpus points to the many topic generalisations and background information on the research topic containing a problem or need statement. This sub-step was originally found by Bunton (2002) as a strategy to establish the niche of the study (Move 2). However, it is found that the statement of problem and need function does not serve to establish the niche of the study. Additionally, this sub-step does not function as a neutral statement as does M1ss2a, as it carries some weight in the writer's rhetorical purpose.

\section{M1ss2b: Problem and Need at the Background Level}

In this study, a statement of the problem or need is considered to be a part of topic generalisation if the statement foregrounds the shortcomings and needs of existing knowledge rather than establishing the niche of the study. An example of a problem statement involving the research world at the background level is presented in Example 15.

\section{Example 15: A statement of problem involving the research world in Thesis 2}

Studies in relation to students' approaches to learning have provided strong evidence that the surface approach to learning is more prevalent in higher education. Research findings reveal that students were more likely to adopt a surface approach to learning if they encountered excessive workload, as well as experienced lack of freedom in their choice of content and method of study (Entwistle, Meyer \& Tait, 1991).

The excerpt from Example 16 shows a statement of need that involves real-world phenomena which is the situation of English in Malaysian education. This statement exhibits a claim of need to strengthen the position of English.

\section{Example 16: A statement of need involving the real-world phenomenon in Thesis 1}

The call to strengthen the position of English as a Second Language in schools has been publicly voiced by the Minister of Education, Datuk Seri Hishamuddin Hussein. He asserts that fluency in English would enable students to compete in an increasingly global world in any field that they choose when they pursue their studies at tertiary level or to enter the workforce (Chin, 2007). 
Another sub-step of background information and topic generalisation is taken when the writer provides positive/negative assumptions regarding a particular phenomenon. Like a statement of problem and need, it carries some weight in the writer's purpose.

\section{M1ss2c: Anticipating the Solution}

Writers only use neutral statements of problems and needs when establishing the territory for their research. The current study also found statements that show the writer's expectations. A statement of M1ss2c in this study reports the writer's positive speculation and assumption of the phenomena as background information. An example of M1ss2c is shown in Example 17.

\section{Example 17: A statement of anticipating the solution in Thesis 1}

Consequently, with eleven years of learning English at school, including two years of learning the language at Matriculation colleges, with the emphasis placed on English in the curriculum one would expect these students to be at least at the intermediate level, as far as their command of English is concerned. Furthermore, with the requirement to complete certain credit hours of English during their studies at universities, one assumes that the graduates would have mastered English well by the time they graduate.

\section{CONCLUSION}

The first information obtained from the analysis was that the amount of attention given to a move varies. As shown previously, thesis writers employed Move 1 the most when introducing the topic under study. The purpose of this move is to furnish the rationale and provide an overview of the study's methodology. This finding is consistent with the research carried out by Arulandu (2005) on master's thesis writing by Malaysians. She found that Move 1 was utilised most in the introductory chapter. Our semantic and functional approach to coding, which was deliberately done to reflect the text, found that presenting problems and needs can also be at the Move 1 level. Here, the writers presented the problems only at the background level and not with direct reference to the topic under study.

What was most evident about the writers establishing the territory in their introductions was the extensiveness of M1s2. In most of the text samples, topic generalisation and background information occupied a major part of the space in the introductory chapter. The primacy of the content encapsulating this step was attributed to the embedded influences of the disciplinary, cultural and socio-political contexts. The characteristics of Social Science and Humanities academic research writing play a significant role in the extensive occurrence of M1s2. When a writer from these disciplines asserts a new perspective for the study, he or she has to depend on many relevant issues to present a highly persuasive and credible argument. This can be carried out by describing the concept and theories of the underlying theme of the study or presenting various methodological approaches and establishing an appropriate approach as well as imparting a personal viewpoint. Therefore, a vast amount of background information regarding the related issues has to be included for readers to accept the writer's theoretical perspective and methodology,

When it comes to explaining the attention given to the M1s2 step, this indirectly relates to one recurring issue concerning socio-cultural influences in traditional contrastive rhetoric studies. This relates to the rhetorical styles of L1 or L2 written discourse: whether they are in a direct or indirect format. The high frequency occurrence of M1ss2a can also be interpreted as the texts being indirect in the sense of displaying lengthy descriptions of the concepts and theories concerning the study topic. Their background information also revolved around 
describing the historical events of the theme being investigated without explaining the importance of such documentations.

A similar strategy was also found in Ahmad's (1997) study of Malay RAIs. One of the RAIs in her study began with a short history of the development of seaweed cultivation in Sabah (a state in West Malaysia) since the wider audience of research articles might be unfamiliar with the local context of the writer's topic. Writers also hope that presenting a lengthy historical event of the theme being analysed would provide the methodological justification for it. For instance, Thesis 8 firstly presented the history of the corpus of the study and then listed various available corpora. This vast information on corpus studies implies that her corpus-based approach to investigating models is valid.

Besides the influence of the reader, the extensive use of M1ss2a might reflect the supervisor's and the supervisory committee's advice. They may have recommended that students provide detailed topical information to demonstrate their knowledge of the field. Another possible context that affects an individual's writing is his or her own writing practice. Since writing a thesis is mostly a solitary act, writers may consult other theses to verify the writing style. The writers in the present study most probably referred to theses from their university or other local universities in Malaysia. Therefore, M1ss2a is traditionally passed down to other writers in the form of textual mentorship.

The indirect manner of presenting arguments can also be seen through the prevalence of M1ss2b. The inclusion of this strategy type is not without its rhetorical rationale. Theses 1 and 5, for instance, look at the communication strategies used by ESL learners and Literature in English in Malaysia respectively. By presenting the historical events as well as the changes in syllabus content, the writers indirectly point out the flaws of the education system. In other words, the declining proficiency of students was the result of the education policy being inconsistent. However, the writers did not explicitly inform readers of this. It is the reader's responsibility to unearth the meaning. The subject of reader-writer responsibility in text comprehension has been a core issue in contrastive studies. As suggested by Connor (2005, p. 38), a piece of writing is incoherent when a writer relies on "appeals to history, tradition, and authority and its frequent references to historical and religious texts as well as proverbs".

The implied intention suggests that the writers did not want to appear to be disrespectful to the government in directly suggesting that the policy initiated the current problematic situation. As this act is considered to be inappropriate and unacceptable, the writers diverted the blame to the teaching classrooms and teachers. Another possible influence on this impliedindirect strategy of imparting negative accounts of information in Move 1 instead of Move 2 is because of writers' personal circumstances as $\mathrm{PhD}$ candidates. Most of the thesis writers in the present study undertook their $\mathrm{PhD}$ with the financial support of a government scheme or scholarship. In the Malaysian academic context, all thesis writers with a scholarship must present their research proposal not only to the university's Senate Committee but also to the Ministry of Higher Education. Hence, the direct criticism of the education system is inappropriate, as this act would mean disobeying the higher authority. A more plausible way to highlight blame is to strategise it circuitously.

Reader-writer responsibility also occurs when the writer asserts claims of needs at the background level. Statements of need at the Move 1 level do not directly suggest that this is the niche of the study. Instead, the intention of the writer is implied. The claim of need is infused in the writer's presentation of historical events regarding Malaysian education. Statements of this kind are common in the introductory chapters of Malaysian theses. Acquiring new knowledge from the study is important for the development of the country. The contribution of knowledge to the country was emphasised through government proclamations and statements by high-ranking officials. For example, Thesis 1 quoted the Prime Minister of Malaysia and Minister of Higher Education to indicate the importance of having English- 
proficient students in order to achieve the country's Vision 2020.

Another point to highlight is the way in which writers impart the importance of the subject or theme to their study which is M1s1: Claiming Centrality. Writers often inform readers about the significance of the topic throughout the introductory chapter. However, most of such centrality statements operate at the real-world knowledge level. Similar to Samraj's (2008) study, most of the writers in the present study explained the importance of the topic at the real-world knowledge level rather than that of research-world knowledge. The issue of disciplinary influence may play a role in the preference of the former. Arguments in Humanities and Social Sciences disciplines have to be persuasive because different readers may have different perspectives on a certain subject. To be persuasive and accepted by readers, writers must frequently present themes that are important and have been globally accepted.

Another Move 1 strategy influenced by the context is M1s3: Reviewing Previous Research (RPR). The functions of RPR in theses differ in their various sections. In the Introduction, RPR plays an important role in providing an overview of previous research on the topic to create the niche of the study. Fakhri (2004, p. 1128) pointed out that to signify the writer's contribution to the topic, extensive discussion of previous research that raises "a gap or a question" must be included. A rhetorical citation to fulfil the aim suggested by Fakhri is one that establishes various sources and reviews them critically. However, only six of the 31 RPRs in the Introduction adopted this strategy. In Malaysia, an argumentative writing style is preached to student learners as early as Year 7. Moreover, universities' writing tasks are also argument-based. Therefore, the unacceptability of argumentative styles cannot be the reason for the lack of RPR in Malaysian writers' texts. The small number of RPR in the study where writers argue and evaluate may be attributed to the existence of the Literature Review chapter. $\mathrm{PhD}$ writers usually provide a detailed discussion of the main concepts and theories or themes of the research in this chapter. It is here that the writer refers to and evaluates previous studies.

As the findings in this study prove, this particular genre is context sensitive. It has some distinctive elements that are socially constructed within the Malaysian setting. Applying the functional-semantic approach to analysis has allowed the expansion of categories whenever any additional features are found. Ultimately, this includes all descriptions and the common functions distinctive to the thesis introductory chapters in Malaysia. This has direct implications for postgraduate student writers. They have to be conscious about the various influences that shape a genre. For this purpose, views of the roles of genre approaches in teaching academic research writing are crucial. In a genre-based pedagogy, students have to possess genre knowledge to be able to see texts as similar or different as well as to respond to them. Hyland (2007) also stressed that writing teachers in NNES classrooms have to realise the importance of genre knowledge in order to conduct an academic writing class. Genre knowledge, as suggested by Hyland (2007, p. 57) consists of the knowledge of the communicative purposes that the genre is commonly used to achieve; knowledge of the appropriate forms that are needed to construct and interpret texts; knowledge of content and register; and knowledge of the contexts in which a genre is regularly found.

\section{REFERENCES}

Ahmad, U. (1997). Research article introductions in Malay: Rhetoric in an emerging research community. In Duszak, A. (Ed.). Trends in linguistics. Studies and monographs 104: Culture and styles of academic discourse (pp. 273-303). New York: Mouton de Gruyter.

Arulandu, M. (2005). Genre analysis of dissertation - Introductions. Master's thesis, University Putra Malaysia, Malaysia.

Bhatia, V. K. (1993). Analysing genre: Language use in professional settings. London: Longman.

Bunton, D. (2002). Generic moves in PhD thesis introductions. In J. Flowerdew (Ed.). Academic discourse (pp. 57-75). London: Longman. 
Cheng, A. (2011). Language features as the pathways to genre: Students' attention to non-prototypical features and its implications. Journal of Second Language Writing. 20(1), 69-82.

Connor, U. (2005). Contrastive rhetoric. Shanghai: Shanghai Foreign Language Education Press.

Fakhri, A. (2004). Rhetorical properties of Arabic research article introductions. Journal of Pragmatics. 36, 11191138.

Hunston, S. (1989). Evaluation in experimental research articles. PhD thesis, University of Birmingham, Birmingham.

Hyland, K. (2007). Genre and second language writing. Michigan: The University of Michigan Press.

Kawase, T. (2018). Rhetorical structure of the introductions of applied linguistics PhD theses. Journal of English for Academic Purposes. 31, 18-27.

Kwan, B. S .C. (2006). The schematic structure of literature reviews in doctoral theses of applied linguistics. English for Specific Purposes. 25, 30-55.

Lewin, B. A., Fine, J. \& Young, L. (2001). Expository discourse: A genre-based approach to social science research text. New York: Continuum.

Lim, J. M. H. (2012). How do writers establish research niches? A genre-based investigation into management researchers' rhetorical steps and linguistic mechanisms. Journal of English for Academic Purposes. 11(3), 229-245.

Lim, J. M. H. (2014). Formulating research questions in experimental doctoral dissertations on Applied Linguistics. English for Specific Purposes. 35, 66-88.

Leshem, S., Bitzer, E. \& Trafford, V. (2018). Writing the Introduction Chapter of PhD Theses. Spaces, Journeys and New Horizons for Postgraduate Supervision. 12, 163-175.

Maznun, M. D. B., Monsefi, R., \& Nimehchisalem, V. (2017). Undergraduate ESL Students' Difficulties in Writing the Introduction for Research Reports. Advances in Language and Literary Studies, 8(1), 9-16.

Samraj, B. (2002a). Texts and contextual layers: Academic writing in content courses. In Johns, A.M. (Ed.), Genre in the classroom (pp. 163-177). Mahwah, NJ: Lawrence Erlbaum Associates, Inc.

Samraj, B. (2005). An exploration of a genre set: Research article abstracts and introductions in two disciplines. English for Specific Purposes. 24(2), 141-156.

Samraj, B. (2008). A discourse analysis of master's theses across disciplines with a focus on introductions. Journal of English for Academic Purposes. 7(1), 55-67.

Soler-Monreal, C., Carbonell-Olivares, M. \& Gil-Salom, L. (2010). A contrastive study of the rhetorical organisation of English and Spanish $\mathrm{PhD}$ thesis introductions. English for Specific Purposes. 1-14.

Swales, J.M. (1990). Genre analysis: English in academic and research settings. Cambridge: Cambridge University Press.

Ventola, E. (1987). The structure of social interaction. A systemic approach to the semiotics of service encounter interaction. London: Pinter. 